CFD Letters

CFI Letters

\title{
Analysis of the Effect of Inlet Velocity on Cooling Speed in a Refrigerated Container using CFD simulations
}

\author{
Muhammad Arif Budiyanto ${ }^{1, *}$, Nadhilah Suheriyanto ${ }^{1}$ \\ 1 Naval Architecture and Marine Engineering, Department of Mechanical Engineering, Universitas Indonesia, Kampus Baru UI Depok, Jawa Barat, \\ 16424, Indonesia
}

\section{ARTICLE INFO}

Article history:

Received 21 October 2020

Received in revised form 22 December 2020

Accepted 22 December 2020

Available online 30 December 2020

Keywords:

Refrigerated container; Inlet velocity;

Temperature distribution; Cooling speed

\section{ABSTRACT}

\begin{abstract}
The use of refrigerated containers continues to increase rapidly in line with global trade, this kind of container is commonly used to deliver perishable cargo from producers to consumers over great distances, even between continents. To avoid perishable goods from damages, the temperature inside refrigerated containers was controlled and maintained to keep the cooling performance. The purpose of this study is to investigate the effect of variation inlet velocity on the cooling speed inside a refrigerated container. This study was conducted through a computational fluid dynamic simulation validated with experimental results. The simulation was carried out on the variations of inlet velocity based on low-speed fan mode at $4 \mathrm{~m} / \mathrm{s}$ equal to 32 circulations/hour, and high-speed fan mode at $10 \mathrm{~m} / \mathrm{s}$ equal to 80 circulations/hour. The results of the simulation show that the greater the inlet fan speed, the faster the cooling speed. The finding of this study is the cooling speed time of high cube refrigerated container with the low-speed fan is 28 minutes and the high-speed fan is 40 minutes.
\end{abstract}

Copyright $\odot 2020$ PENERBIT AKADEMIA BARU - All rights reserved

\section{Introductions}

The growth of refrigerated shipping containers continues to increase along with the development of the global shipping containers market. Refrigerated containers are expected to be the fastestgrowing segment in the category of product form during the period 2017-2025, the optimistic forecast increased by 10.2 percent [1]. Refrigerated containers are widely used for shipping perishable cargoes from producers to consumers over long distances [2]. It is important to control temperature, airflow, and humidity to maximize the operation of refrigerated containers [3]. Many factors affect the performance of refrigerated container operation, namely controlling environmental conditions, structuring cargo pallet, and thermal insulation of containers [4-6], it also depends on temperature fluctuations and product respiration rates as well as airflow circulation [7].

\footnotetext{
* Corresponding author.

E-mail address: arif@eng.ui.ac.id (Muhammad Arif Budiyanto)
} 
Several studies to improve the performance of refrigerated containers and related to their energy consumption have been carried out. In terms of increasing the efficiency of refrigeration systems, researchers have conducted many experiments in the use of natural coolant [8] and nano refrigerant [9]. Research on controlling environmental conditions has also been carried out by several researchers, one of the experiments using a roof-shade that effectively reduces heat penetration from the environment [10], in addition to the effects of stack containers also showed an influence on the energy consumption of refrigerated containers [11]. From the improvement of the thermal insulation of containers, some researchers trying to use phase change material [12], the results were quite good in maintaining the cooling load in the cargo [13], besides the influence of direct sunlight also caused heat penetration to thermal insulation [14].

Some researchers performed the simulation of the refrigerated container related to the heat transfer and fluid flow [15]. The application of computational fluid dynamics (CFD) simulation to study operational and design parameters in cold storage technology has become popular in recent decades [16]. The development of CFD research on cold storage starts with broader research in the field of HVAC (heating, ventilation, and air conditioning) [17] in buildings and the environment to observe cooling performance and thermal comfort [18], one of which begins in the analysis of air distribution in small offices [19]. Several studies about the energy saving of the refrigerated container have been done by considering the effect of the angle [20] and environmental condition [21], the results showed good results compared to the experiment. Related to the temperature distribution, the effects of the cooling characteristics have been investigated, the results show that the inlet fan speed has caused different cooling distribution and related to the cargo arrangement [22]. The airflow circulation generally depends on the setting of the fan evaporator, typically there are two settings used i.e. low-speed fan and high-speed fan [23].

The knowledge of cooling speed related to the fan setting in practical operation will provide good practice for operators to improve cargo cooling distribution. From most of the existing literature studies, research on cargo cooling systems is mostly done on energy consumption and refrigeration performance, not many studies have been done in the practical uses such as the effect of fan setting on the cooling speed of cargo. The purpose of this study is to investigate the effect of variation inlet velocity on the cooling speed inside a refrigerated container. This study was conducted through a computational fluid dynamic simulation validated with experimental results. The contribution of this study is the cooling speed inside the refrigerated container with the various settings of inlet velocity.

\section{Methodology}

\subsection{Simulation Model of Refrigerated Container}

In global container shipping, there are two types and sizes of refrigerated containers, namely porthole refrigerated containers and integral refrigerated containers of $20 \mathrm{ft}$ and $40 \mathrm{ft}$ respectively. The majority of container types used today are integral refrigerated containers. In this study, we carry out a three-dimensional simulation to analyze the temperature distribution inside high-cube refrigerated containers. The simulation model of the refrigerated container was used $40 \mathrm{ft}$ high-cube refrigerated container with considering the insulation walls and evaporator inlet also cargo outlet. The sectional view and the main dimension of $40 \mathrm{ft}$ high-cube refrigerated containers are shown in Figure 1. 


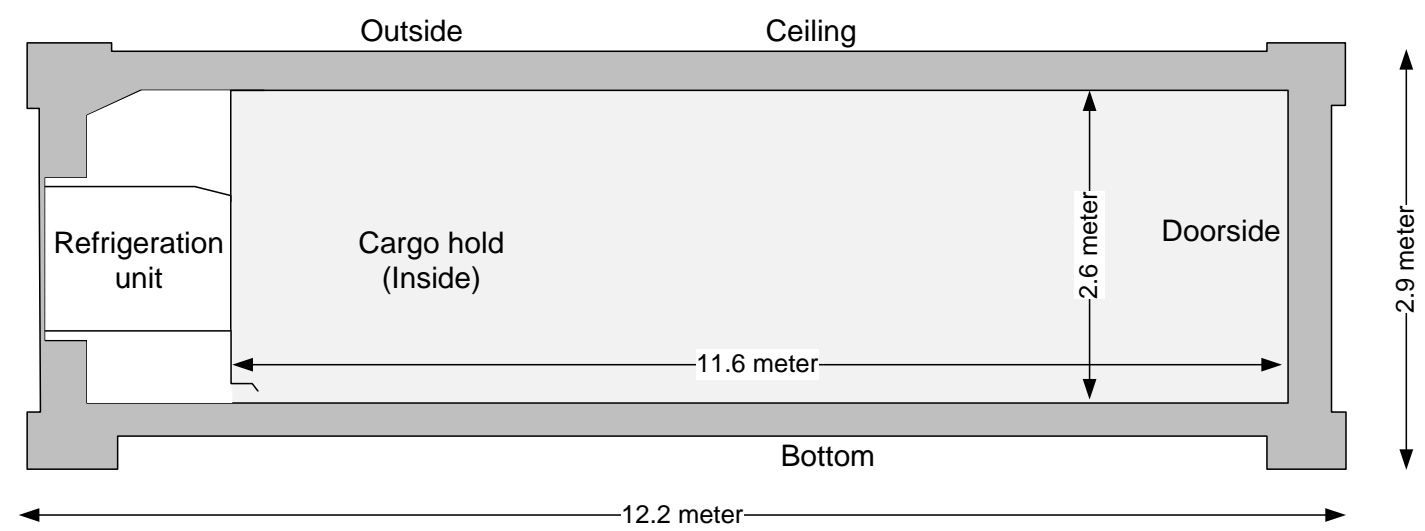

Fig. 1. Geometry of high cube refrigerated container

The simulation model is based on the solution of partial differential equations that govern the flow of fluid flow fields based on the mass and momentum conservation as well as energy equations as shown in Eq. (1), Eq. (2) and Eq. (3), respectively.

$\nabla \cdot v=0$

$\rho\left(\frac{\partial \mathbf{v}}{\partial t}+\mathbf{v} \cdot \nabla \mathbf{v}\right)=-\nabla p+\mu \nabla^{2} \mathbf{v}+f_{B}$

$\int_{V} \rho C_{p}\left(\frac{\partial T}{\partial t}+\boldsymbol{v} \cdot \nabla T\right) d V=\int_{V} k \nabla^{2} T d V+\int_{S}\left(q_{R}+q_{S}\right) d S$

Where $\boldsymbol{V}$ is velocity vector $(\mathrm{m} / \mathrm{s}), \quad \rho$ is the density of air $\left(\mathrm{kg} / \mathrm{m}^{3}\right), \boldsymbol{P}$ is pressure $\left(\mathrm{N} / \mathrm{m}^{2}\right), \boldsymbol{\mu}$ is coefficient of viscosity (N.s/m²), $\boldsymbol{t}$ is time function (s) and $\boldsymbol{f}_{B}$ is the buoyant force. In this study, the $\boldsymbol{k}$ $\boldsymbol{\omega}$ shear stress transport turbulence model is used because it has been shown to perform better than other turbulence models, based on the results of the review and current latest developments, this model has established a rough boundary treatment method that requires the same grid resolution as smooth boundary treatment methods, but the impact of grid resolution on the computed velocity is high $[24,25]$. The density of air is assumed to be constant at the cooling air temperature of $-0.5{ }^{\circ} \mathrm{C}$. Details of the parameter setting of simulation models are shown in Table 1.

\subsection{Boundary Condition and Parameter Setting}

The basic assumption of the simulation model starting from cold air enters the cargo room through evaporator inlet with certain speed variation, cold air is circulated into the refrigerated container cargo room, then circulated air exits through an outlet located on the ceiling. The inlet speed variation has been determined as is a low-speed to high-speed fan i.e. $4 \mathrm{~m} / \mathrm{s}, 6 \mathrm{~m} / \mathrm{s}, 8 \mathrm{~m} / \mathrm{s}$, and $10 \mathrm{~m} / \mathrm{s}$. In practical operation, the low-speed fan setting is 32 circulation/hour, and the high-speed fan setting 80 circulation/hour [26]. As a boundary condition, this model uses the no-slip condition for viscous fluid assuming that at solid limits, the fluid will have zero velocity relative to the boundary. The physical properties of the air are assumed to be constant and the outlet airflow velocity does not differ across the width of the outlet unit. The total number of mesh generation is 783395 elements. The boundary condition and mesh generation of the simulation model are shown in Figure 2 . 

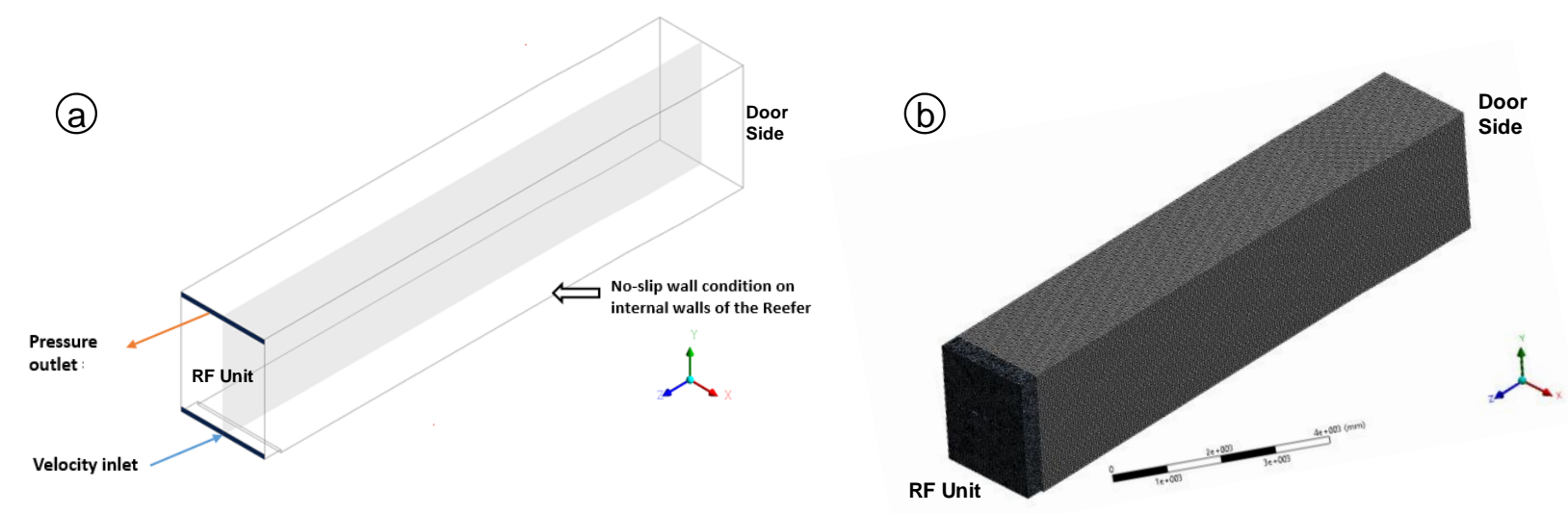

Fig. 2. (a) Boundary condition of simulation mode; (b) Structured mesh generation

Table 1

Parameter setting of simulation models

\begin{tabular}{ll}
\hline Simulation Parameter & Setting Condition \\
\hline The geometry of the simulation & Length $11.58 \mathrm{~m}$ \\
model & Width $2.27 \mathrm{~m}$ \\
& Height $2.54 \mathrm{~m}$ \\
Timestep & Transient \\
Turbulence model & $\mathrm{k}-\omega$ \\
Number of mesh & 783395 elements \\
Inlet area & $0.145 \mathrm{~m} 2$ \\
Inlet temperature & $-0.5{ }^{\circ} \mathrm{C}$ \\
Inlet velocity & $4 \mathrm{~m} / \mathrm{s}$ \\
& $6 \mathrm{~m} / \mathrm{s}$ \\
& $8 \mathrm{~m} / \mathrm{s}$ \\
& $10 \mathrm{~m} / \mathrm{s}$ \\
\hline
\end{tabular}

\section{Results and Discussion}

\subsection{Validation of Simulation Model}

In this study, the results of the CFD simulation were validated with experimental data that had been done previously both for stack container and single containers with an empty load condition $[11,14,27]$. The experiment used the same type of container, namely a $40 \mathrm{ft}$ high-cube refrigerated container. The condition when the experiment was set without any charge, then the cooling system was turned on and empty from the start of use at ambient temperature until the desired temperature was $0^{\circ} \mathrm{C}$, so that the experiment represented a cooling speed. The validation of the CFD simulation results with experimental data is shown in Figure 3. The validation was carried out at a fan speed of $4 \mathrm{~m} / \mathrm{s}$, from the comparison results obtained a good trend line between simulation and experiment, the smallest deviation is $\pm 0.2^{\circ} \mathrm{C}$, while the largest deviation is $\pm 1.4^{\circ} \mathrm{C}$. From the results of simulations and experiments, it can be seen that to get the desired temperature of $0^{\circ} \mathrm{C}$ it takes about 40 minutes from the start of use with a fan speed of $4 \mathrm{~m} / \mathrm{s}$. The temperature distribution at 15 minutes is shown in Figure 4. From this distribution, it can be seen that the bottom part of the floor where parallel to the inlet gets a better cool air blast effect than the top side. The evaporator inlet, which is $0^{\circ} \mathrm{C}$ cold air, is at the bottom on the left side, the inlet area is very limited, which is $0.145 \mathrm{~m}^{2}$. This makes the cold air jet fairly well parallel to the bottom of the container compartment. At a distance of about 9 meters from the inlet, the cold air jet is not too strong, so the temperature at the end of the container close to the door (right side) tends to be higher than that of the evaporator. This needs to be of 
particular concern in arranging cargo in the container room so that cold air can be spread throughout the room. This is interesting when it is related to the cooling load of the cargo contents to be transported so that the temperature distribution can be uniform throughout the room.

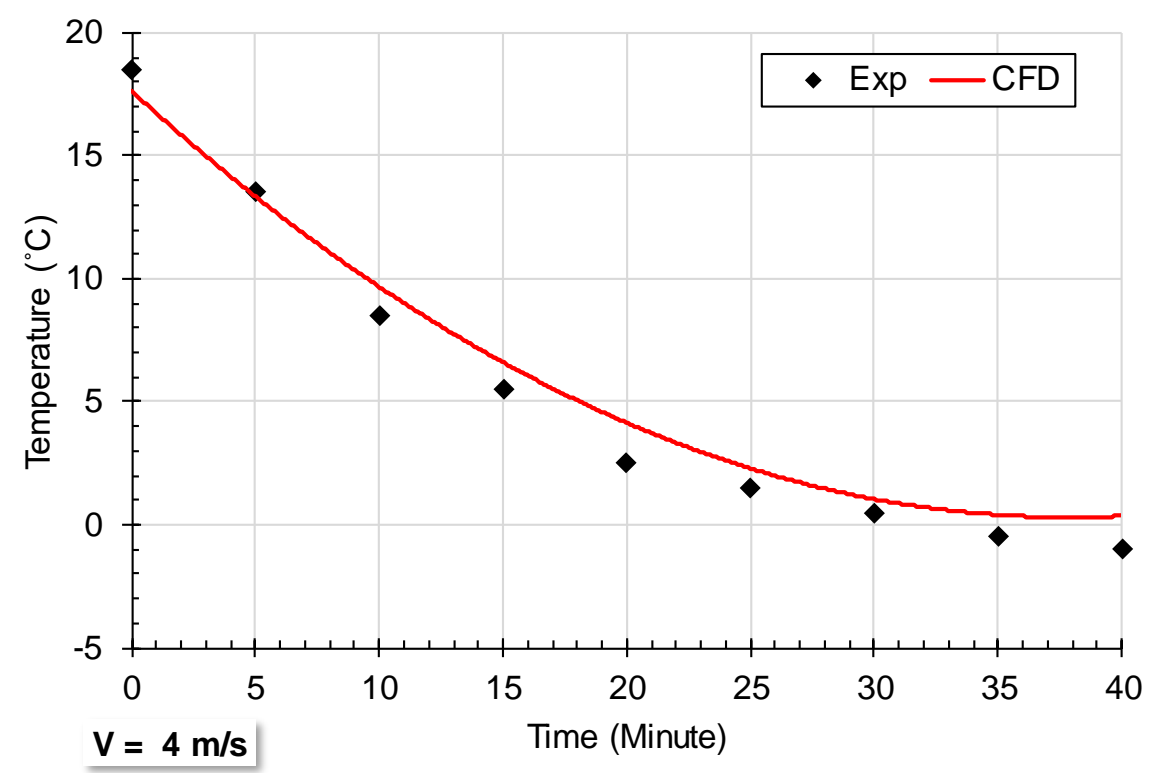

Fig. 3. Validation of temperature result between experiment and simulation with inlet velocity $4 \mathrm{~m} / \mathrm{s}$
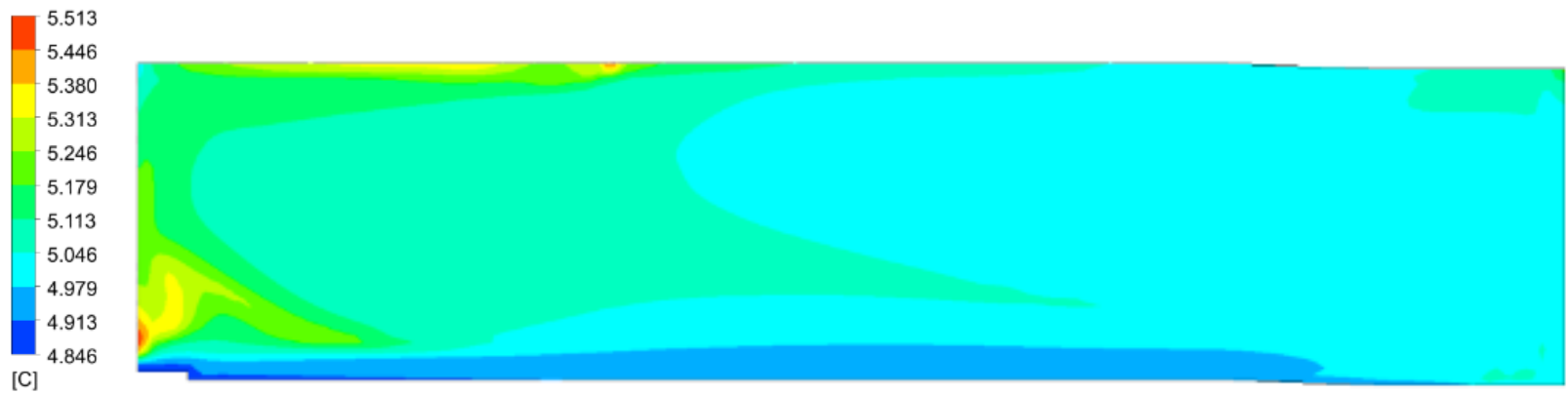

Fig. 4. Temperature distribution with inlet velocity $4 \mathrm{~m} / \mathrm{s}$ after 15 minutes

\subsection{Variation of Inlet Velocity}

The effect of variations in inlet velocity on cooling speed is shown in Figure 5 . The variations in inlet speed used are $4 \mathrm{~m} / \mathrm{s}, 6 \mathrm{~m} / \mathrm{s}, 8 \mathrm{~m} / \mathrm{s}$, and $10 \mathrm{~m} / \mathrm{s}$. From the variation in inlet speed, it is clear that an increase in inlet speed will accelerate the cooling time. To get the desired temperature of $0^{\circ} \mathrm{C}$ with low-speed to high-high speed fans, namely 40 minutes, 36 minutes, 32 minutes, and 28 minutes, respectively. From these results, it is found the cooling speed time on the low-speed fan is $4 \mathrm{~m} / \mathrm{s}$ is 28 minutes and high-speed fan $10 \mathrm{~m} / \mathrm{s}$ is 40 minutes, which the difference is up to 12 minutes. This cooling speed is important when the operator wants to set the temperature level of the load to be carried. This is interesting to study in further research if the container is given a cooling load. 


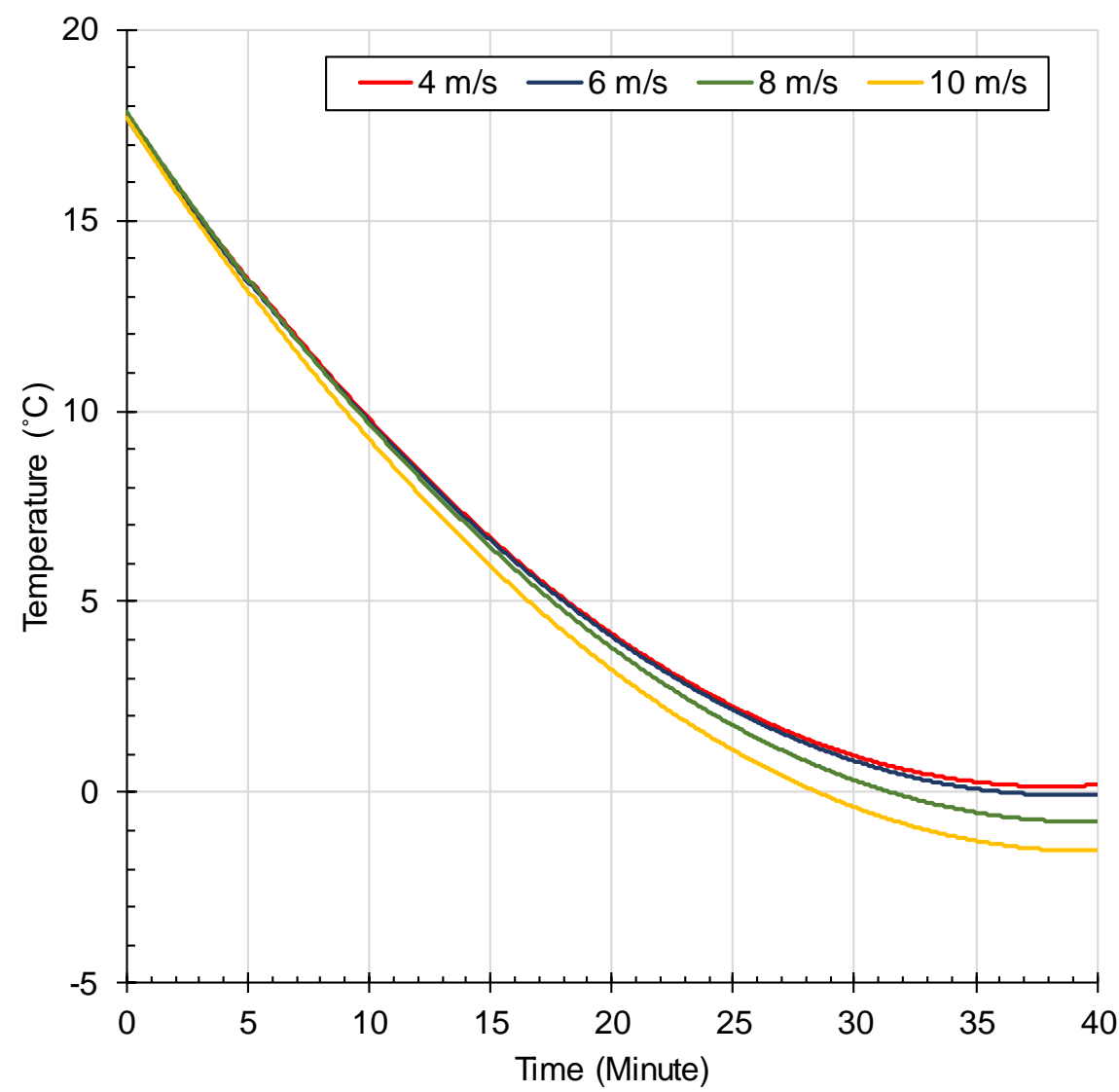

Fig. 5. Effect of variation inlet velocity to the cooling speed

\section{Conclusions}

A study of the effect of variation inlet velocity to the cooling speed inside high-cube refrigerated containers has been performed using CFD simulations and validated using experimental data. Four variations of inlet velocity have been investigated i.e. $4 \mathrm{~m} / \mathrm{s}, 6 \mathrm{~m} / \mathrm{s}, 8 \mathrm{~m} / \mathrm{s}$, and $10 \mathrm{~m} / \mathrm{s}$. The variation is based on low-speed fan mode at $4 \mathrm{~m} / \mathrm{s}$ equal to 32 circulations/hour, and high-speed fan mode at $10 \mathrm{~m} / \mathrm{s}$ equal to 80 circulations/hour. The simulation result of cooling speed inside the refrigerated container has good agreement with the previous experimental data. The interesting finding of this study is the cooling speed time on the low-speed fan $(4 \mathrm{~m} / \mathrm{s})$ is 28 minutes and the high-speed fan $(10 \mathrm{~m} / \mathrm{s})$ is 40 minutes, which the difference is up to 12 minutes. This time can be used as a benchmark for an operator to adjust the cooling speed of the cargo loaded in the refrigerated container.

\section{Acknowledgment}

With the support for article publication by PUTI Q3 NKB-2011/UN2.RST/HKP.05.00/2020, the authors wished to thank the Directorate of Research and Development (DRPM) Universitas Indonesia.

\section{References}

[1] Persistence Market Research. Shipping Containers Market - Global Growth, \& Forecast to 2025.

[2] Fitzgerald, Warren B., Oliver JA Howitt, Inga J. Smith, and Anthony Hume. "Energy use of integral refrigerated containers in maritime transportation." Energy Policy 39, no. 4 (2011): 1885-1896. https://doi.org/10.1016/i.enpol.2010.12.015

[3] Getahun, Samuel, Alemayehu Ambaw, Mulugeta Delele, Chris J. Meyer, and Umezuruike Linus Opara. "Analysis of 
airflow and heat transfer inside fruit packed refrigerated shipping container: Part I-Model development and validation." Journal of food engineering 203 (2017): 58-68.

https://doi.org/10.1016/i.jfoodeng.2017.02.010

[4] Defraeye, Thijs, Bart Nicolai, Wayne Kirkman, Sean Moore, Sonnica van Niekerk, Pieter Verboven, and Paul Cronjé. "Integral performance evaluation of the fresh-produce cold chain: A case study for ambient loading of citrus in refrigerated containers." Postharvest Biology and Technology 112 (2016): 1-13. https://doi.org/10.1016/i.postharvbio.2015.09.033

[5] Louw, Louis, and S. Nel. "Analysis of the use of space and module-configured packaging to improve fruit export mass in a refrigerated container." South African Journal of Industrial Engineering 30, no. 1 (2019): 94-109.

https://doi.org/10.7166/30-1-1879

[6] Zheng, Q. R., Z. W. Zhu, J. Chen, and W. S. Yu. "Preparation of carbon based getter for glass fiber core vacuum insulation panels (VIPs) used on marine reefer containers." Vacuum 146 (2017): 111-119. https://doi.org/10.1016/i.vacuum.2017.09.040

[7] Castelein, Bob, Harry Geerlings, and Ron Van Duin. "The reefer container market and academic research: a review study." Journal of Cleaner Production (2020): 120654.

https://doi.org/10.1016/j.jclepro.2020.120654

[8] König, H. "Practical tests with R290 used in reefer container refrigeration-leakage testing." (2016).

[9] Dhamneya, Amrat Kumar, S. P. S. Rajput, and Alok Singh. "Comparative performance analysis of ice plant test rig with TiO2-R-134a nano refrigerant and evaporative cooled condenser." Case studies in thermal engineering 11 (2018): 55-61. https://doi.org/10.1016/i.csite.2017.12.004

[10] Budiyanto, Muhammad Arif, and Takeshi Shinoda. "Energy efficiency on the reefer container storage yard; an analysis of thermal performance of installation roof shade." Energy Reports 6 (2020): 686-692.

https://doi.org/10.1016/i.egyr.2019.11.138

[11] Budiyanto, Muhammad Arif, and Takeshi Shinoda. "Stack effect on power consumption of refrigerated containers in storage yards." International Journal of Technology 8, no. 7 (2017): 1182-1190. https://doi.org/10.14716/ijtech.v8i7.771

[12] Michel, Benoit, Patrick Glouannec, Adrien Fuentes, and Philippe Chauvelon. "Experimental and numerical study of insulation walls containing a composite layer of PU-PCM and dedicated to refrigerated vehicle." Applied Thermal Engineering 116 (2017): 382-391. https://doi.org/10.1016/j.applthermaleng.2016.12.117

[13] Copertaro, Benedetta, Paolo Principi, and Roberto Fioretti. "Thermal performance analysis of PCM in refrigerated container envelopes in the Italian context-Numerical modeling and validation." Applied thermal engineering 102 (2016): 873-881. https://doi.org/10.1016/i.applthermaleng.2016.04.050

[14] Budiyanto, Muhammad Arif, and Takeshi Shinoda. "The effect of solar radiation on the energy consumption of refrigerated container." Case studies in thermal engineering 12 (2018): 687-695.

https://doi.org/10.1016/i.csite.2018.09.005

[15] Budiyanto, Muhammad Arif, and Takeshi Shinoda. "Study on the CFD simulation of refrigerated container." In IOP Conference Series: Materials Science and Engineering, vol. 257, no. 1, p. 012042. IOP Publishing Ltd., 2017. https://doi.org/10.1088/1757-899X/257/1/012042

[16] T.. M. Velayudhan and M.. Yameni. "A review on selection of turbulence model for CFD analysis of air flow within a cold storage." In IOP Conf. Ser. Mater. Sci. Eng, 197 012057, 36, pp. 10-12.2012.

[17] Ismail, Mohd Azmi, and Mohd Sabri Che Jamil. "CFD HVAC Study of Modular Badminton Hall." CFD Letters 12, no. 7 (2020): 90-99. https://doi.org/10.37934/cfdl.12.7.9099

[18] Widiastuti, Ratih, Juliana Zaini, Mochamad Agung Wibowo, and Wahyu Caesarendra. "Indoor Thermal Performance Analysis of Vegetated Wall based on CFD Simulation." CFD Letters 12, no. 5 (2020): 82-90. https://doi.org/10.37934/cfdl.12.5.8290

[19] Hatif, Ihab Hasan, Azian Hariri, and Ahmad Fu'ad Idris. "CFD Analysis on Effect of Air Inlet and Outlet Location on Air Distribution and Thermal Comfort in Small Office." CFD Letters 12, no. 3 (2020): 66-77. https://doi.org/10.37934/cfdl.12.3.6677

[20] Budiyanto, Muhammad Arif, Haris Fernanda, and Takeshi Shinoda. "Effect of azimuth angle on the energy consumption of refrigerated container." Energy Procedia 156 (2019): 201-206. https://doi.org/10.1016/i.egypro.2018.11.128

[21] Budiyanto, Muhammad Arif, and Fariz Zhafari. "Simulation study using building-design energy analysis to estimate energy consumption of refrigerated container." Energy Procedia 156 (2019): 207-211. 
https://doi.org/10.1016/j.egypro.2018.11.129

[22] Getahun, Samuel, Alemayehu Ambaw, Mulugeta Delele, Chris J. Meyer, and Umezuruike Linus Opara. "Experimental and numerical investigation of airflow inside refrigerated shipping containers." Food and Bioprocess Technology 11, no. 6 (2018): 1164-1176. https://doi.org/10.1007/s11947-018-2086-5

[23] Wild, Yves. "Refrigerated containers and CA technology." Container Handbook 3 (2009).

[24] Menter, Florian R. "Review of the shear-stress transport turbulence model experience from an industrial perspective." International journal of computational fluid dynamics 23, no. 4 (2009): 305-316. https://doi.org/10.1080/10618560902773387

[25] Lee, Cheng-Hsien. "Rough boundary treatment method for the shear-stress transport k- $\omega$ model." Engineering Applications of Computational Fluid Mechanics 12, no. 1 (2018): 261-269. https://doi.org/10.1080/19942060.2017.1410497

[26] Van Ameyde Marine. Airflow in reefer containers circulation and ventilation explained.

[27] Budiyanto, Muhammad Arif, Takeshi Shinoda, Firman Ady Nugroho, and Buddi Wibowo. "Estimated of energy saving from the application of roof shade on the refrigerated container storage yard." Journal of Advanced Research in Fluid Mechanics and Thermal Sciences 46, no. 1 (2018): 114-121. 